\title{
M. MERLEAU-PONTY AND LUDWIG \\ WITTGENSTEIN: A SYNTHESIS
}

\section{DENNIS E. HEINZIG \\ University of Kansas}

At first sight it might appear that M. Merleau-Ponty and Ludwig Wittgenstein are strange allies; for phenomenology and analytic philosophy have long been considered incompatible. However, greater insight into the similarities between the two philosophers will show that the phenomenology of MerleauPonty is a foundation for a phenomenal world in which a Wittgensteinian philosophy may flourish, though not at the expense of that foundation, but to form a more complete and comprehensive philosophy. After such a synthesis of Wittgensteinian philosophy and Merleau-Ponty's phenomenology of perception, where Wittgenstein grows silent, when we reach beyond the 'language-games' and 'forms of life,' once again the phenomenology of Merleau-Ponty presents itself to point toward the Beyond. The precedence and succession of Merleau-Ponty to Wittgenstein is not a temporal or honorary one, but rather, a logical or phenomenological one. For Merleau-Ponty dares to tread where language fears to go; cannot go. While Wittgenstein has restricted himself to ordinary language, Merleau-Ponty has advocated the primacy of perception. Together, however, they find themselves "condemned to meaning." 1

It is precisely at the source of meaning that Merleau-Ponty constructs a foundation on which Wittgenstein can build. The foundation is phenomenologically prior to personal consciousness. Merleau-Ponty calls such a 'place' the 'phenomenal field,' which is bounded by horizons that limit and structure its scope. There, in the phenomenal field that is pre-personal, pre-reflective, non-thematic, meaning occurs when the polarities of subject and object coincide. Only in several unique relationships is meaning possible. Without a

I am grateful to Eward G. Lawry for his comments on earlier drafts of this essay.

${ }^{1} \mathrm{M}$. Merleau-Ponty, Phenomenology of Perception (New Jersey: The Humanities Press, 1962), p. XIX. 
subject, nothing exists; without an object, nothing exists. Both are mutually interdependent and inseparable. They are two polarities in a relationship out of which springs the vivacity that is being and the world. One cannot ask nor say 'where' the world was or how it existed prior to its perception, nor the same concerning any subject prior to the disclosure of the world to it. For one without the other is naught. As a rainbow appears as the manifestation of the intimacy of sunlight and rain, so being-in-the-world occurs as the only possible avenue to the intimacy of subject and world. Phenomenologically prior to the existence of that which is personal to utter an 'I,' before the consciousness experiences its own reflection, the body-subject (as Merleau-Ponty labels it) reaches out with a primitive openness to the world in the heart of the 'context' that is the phenomenal field, to grasp into itself the physiognomies that present themselves before the backgrounds that stand out from the phenomenal field and the horizon surrounding it. This is the first world of the trilogy presented by Merleau-Ponty. It is here, in the pre-personal world, that the primacy of perception gets established and the foundation for phenomenology is laid. For anterior to it one cannot penetrate, and posterior from it one cannot construct such a foundation, as the failures of empiricism and intellectualism have adequately shown. ${ }^{2}$

It is indeed in this perceptual event that consciousness 'happens' as perception in its quasi-teleological reach which intentionally extends to the object of perception, and 'means' it as it is itself 'meant' by that object. In that existential reciprocity, that polarity of perceiver and perceived, the consciousness is taunted, drawn, and seduced to meaning.

Consciousness does not begin to exist until it sets limits to an object, and even the phantoms of 'internal experience' are possible only as things borrowed from external experience. Therefore consciousness has no private life, and the only obstacle it encounters is chaos, which is nothing. ${ }^{3}$

${ }^{2}$ Gary Brent Madison, The Phenomenology of Merleau-Ponty: A Search for the Limits of Consciousness (Athens: Ohio University Press, 1981), pp. 24-7.

${ }^{3}$ Merleau-Ponty, pp. 27-28. 
This limitation is not a constituting consciousness like that of Kant, but rather, a perceiving consciousness that attempts to define a horizon of meaning that forms the object of perception, which discloses itself as a physiognomy before a background. 'The perceptual 'something' is always in the middle of something else, it always forms part of a 'field'. ${ }^{\text {"4 }}$ From this field surrounded by its horizon springs the background which presents a physiognomy to the intending perceptual consciousness. Because, in the phenomenal field 'this' side of the horizon, the background steps forth offering an object for perception that stands before such a background, meaning is made possible. For in perception, the 'space' between the perceiving consciousness and the physiognomy, the physiognomy and the background, and the background and the horizon is depth, which is an existential dimension. ${ }^{5}$ Those items, standing in such a relation to each other, create existential relations that are the 'meaning' of consciousness.

Our perceptual field is made up of 'things' and 'spaces' between things! ${ }^{6}$

The perceived world is structured according to the hold that body has or can have on it. The spatiality of the perceived world is thus a reply to the body's dimensions and its possibilities for action?

This makes the presence of the body-subject the 'here' as it stands in existential relation to the 'there' of the object of perception, which is made possible (to stand forth from) by the background and phenomenal field. Because this body-subject and object of perception are inseparable, they are in a unified polarity of 'here' and 'there' simultaneously. It can only follow that such a collapse of 'space' would place consciousness nowhere and everywhere.

I am a consciousness, a strange creature which resides nowhere and can be everywhere present in intention. Everything that exists exists as a thing or as a consciousness, and there is no halfway house. The thing is in a place, but perception is nowhere.

4 Merleau-Ponty, p. 4.

5 Merleau-Ponty, p. 267.

6Merleau-Ponty, p. 15.

${ }^{7}$ Madison, p. 29. 
.. Its incarnation furnishes no positive characteristic which has to be accounted for, and its thisness (ecceity) is simply its own ignorance of itself. 8

The 'here' of the body-subject is its presence in the world. The 'here' is not a space in a geometrical system of relations, a euclidean space, but rather, an existential space, a dimension of meaning that takes place 'here.' 'Here' is the embodied or incarnate consciousness. Consciousness and the body are perceptually indistinguishable. This is the body-subject, that totality that is body and consciousness. This body-subject seen as the body image is the body that I live, perceive as, 'where' I am at 'home'.

The phenomenal body is to be understood as an 'expressive unity', a synergic system, to be compared not to a physical object but to a work of art. It is the seat of intentionality, so that in projecting itself onto the world, it makes the world the arena for my intentions.?

The body viewed merely as a physical object as in physiology is the objective body. However, I live and move my phenomenal (lived) body. It is what I reach from and through as I intend the object of my perceptions and receive that object from the world as it is meant to me. It is precisely this intentional relationship that is definitive of both body-subject and the world, and only in such a synthesis of those two polarities is the physiognomy of the world given to the bodysubject through sensation, and is the body cast into the object of perception which 'thinks itself' in that subject. ${ }^{10}$ Thus the world as the object of perception is for that perceiving subject, and that subject is for the world as being-in-the-world and as the possibility of the being of the object so perceived. Therefore the body-subject can only maintain its 'here' (i.e. position in the phenomenal field) as being-in-the-world if there is a world in which to be, and the world can only 'be' if

${ }^{8}$ Merleau-Ponty, pp. 37-8.

${ }^{9}$ Laurie Spurling, Phenomenology and the Social World, The Philosophy of Merleau-Ponty and its relation to the social sciences (London: Routledge \& Kegan Paul, 1977), p. 22.

${ }^{10}$ Madison, pp. 27-8. 
there is a perceiving subject for which to be. That subject, however, can only 'be' to provide and thercfore allow the being of the world if the world is 'there' to be perceived and thus grant being to the body-subject. Such a synthesis is not complete for even though the world and the body-subject are mutually dependent on each other, the world always outruns the subject's perception of it. Thus, it is the case that the above synthesis is only partial and contingent, not the coinciding of the subject with the world. ${ }^{11}$ As John O'Neil expresses it,

We understand the world and the objects it presents to us in a level of symbiosis ... To possess a body that is capable of innersensory synergy is to possess a universal setting or schema for all possible styles or typical structures in the natural world ...12

Although this symbiosis exists with a single subject, it shall be assumed in this essay that there is a plurality of subjects each of which perceives the world. The world is an intersubjective perception; the world sustaining and creating the possibility for subjects and subjects for the world. Spurling explains,

There is intersubjectivity because all experience opens into a common world. Experience understood phenomenologically, is essentially open: it blends with other experiences of mine to create structures and patterns, and blends with the experiences of other persons to create intersubjective meanings to found communication. ${ }^{13}$

This is the basis for the social world which, like the phenomenal world, is primordial. ${ }^{14}$ It is the world of language. For without language there could exist no human world, no social world. There could be no intersúbjectivity. All bodysubjects, if one can even say there would be such, would be

${ }^{11}$ Albert Rabil, J. R., Merleau-Ponty: Existentialist of the Social World (New York: Columbia University Press, 1967), pp. 32-5.

12John O'Neill, Perception, Expression and History, The Social Phenomenology of Maurice Merleau-Ponty (Evanston: Northwestern University Press, 1970), p. 17.

${ }^{13}$ Spurling, p. 41.

${ }^{14}$ Rabil, p.36. 
forever isolated and banished to rampant individualism and relativity to such singleness. O'Neil cogently points this out:

Through language we first encounter that system of exchanges between consciousness and the world in which meaning is established and renewed in a permutation of the given and the possible which offers a paradigm of all cultural institutions, for it is the matrix of the acquisition and renewal of the tradition of humanity in each of us.

Through language I discover myself and others, in talking, listening, reading, and writing. It is language which makes possible that aesthetic distance [depth] between myself and the world through which I can speak about the world and the world in turn can speak through me. Our thoughts and purposes are embodied in bodily gestures ... and thus we make our world. ${ }^{15}$

The social or human world and even humankind itself is inconceivable without language. Language is the way one lives outside oneself in a symbolic world of meaning that is beyond the phenomenal world. There is nothing that illuminates the intersubjectivity of the world better than language. It reveals both one's individuality and the universality of life. Language surrounds us, engulfs us, permeates us. It is the existential 'air' that we breathe, move in, and live through. It sustains us, grounds us, and allows us to transcend ourselves to meaning that is above the pre-personal, phenomenal world. It is the very 'Life' of the social world. ${ }^{16}$

In the second world of Merleau-Ponty, Wittgenstein makes his home. Wittgenstein's linguistic philosophy precisely illuminates the intersubjective linguistic characteristic that is inherent in this social world. Because of the linguistic ties, and only so, is intersubjectivity possible, propagated and continuing. The interpermeation of language and subjectivity to intersubjectivity is much like that of the relation of perception and the object of perception. One without the other results in both being annihilated. They are mutually interdependent. Because the intersubjectivity of the social world is such, my perceptions of the phenomenal world can share with others the commonly held assumptions and expectations about the

${ }^{15}$ O'Neill, pp. 61, 64.

16Madison, p. 121. 
perceptual world. Like the phenomenal world, the 'linguistic world' is given to us prereflectively. "Language is a signifying system ... something 'already there', something the members of a linguistic community have inherited and not constituted .. "17 It is the meaning that is given to us, intersubjectively, by the social (linguistic) world as meaning is given to us by the phenomenal world. This is, then, the appropriate starting point for a linguistic philosopher like Wittgenstein. Though it may seem strange to synthesize phenomenology and linguistic analysis, I shall attempt to show the ease with which such a synthesis is not only possible but naturally compatible with Merleau-Ponty's notion of this social world. Spurling has already testified to such.

We see here a striking convergence with Merleau-Ponty's phenomenology of speech - in Wittgenstein's stress on meaning as use in context, his analogy between words and tools, his rejection of meaning as an internal, mental activity, to say nothing of his definition of understanding in existential rather than conceptual terms, as the mastery of a technique, involving the ability to carry out what is intellectually grasped. ${ }^{18}$

The above quotation clearly states an important point in this synthesis. For, existentially, Wittgenstein and MerleauPonty are in the same dimension, though perhaps it must be granted that their respective techniques do vary. Wittgenstein begins by rejecting the nominalistic conception of language espoused by Augustine and a great many other philosophers that followed him. Language 'lives' for us in a variety of ways and cannot be simplistically contained in 'this' box .or 'that' one. As the object of perception 'outruns' the perception, so words 'outrun' our simple classification of how they exist for us.

There are countless kinds: countless different kinds of use of what we call 'symbols', 'words', 'sentences'. And this multiplicity is not something fixed, given once for all; but new types of language,

17Madison, p. 121.

${ }^{18}$ Spurling, p. 64. 
new language-games, as we may say, come into existence, and others become obsolete and get forgotten. ${ }^{19}$

The fluidity of language is analogous to that of perceptual phenomena. As the perception of phenomena is meaningful only as it stands out from the background 'behind'. it, and that background rises out of the phenomenal field 'this' side of the horizon, and meaning comes forth; so it is with language. For, as Wittgenstein correctly shows, meaning in the social (linguistic) world happens in the same fashion. Words and sentences (the phenomena of the social world) stand in a particular 'context', a linguistic field, that is also surrounded by a horizon that Wittgenstein will call 'rules' of 'grammar'. It is precisely this context and the given 'use' of a word that are the meaning of it, the use being roughly analogous to the 'background' before which a word stands out. When a word is perceived one sees not only how it is 'used', i.e. which background against which it is displayed, but also the context of the use, i.e. where in the linguistic (analogously, phenomenal) field it occurs or stands out. If it were not used in a context provided by 'rules' (horizons of meaning) there could be no 'meaning' at all. For, mere jibberish would only result. As subject and the world without each other are annihilated, so speaker/listener and linguistic field without each other are nonexistant.

Compare the following quotations from Wittgenstein and Merleau-Ponty, respectively:

Though - one would like to say - every word has a different character in different contexts, at the same time there is one character it always has: a single physiognomy. It looks at us. ${ }^{20}$

Words have a physiognomy because we adopt towards them, as toward each person, a certain form of behavior which makes its complete appearance the moment each word is given. ${ }^{21}$

${ }^{19}$ Ludwig Wittgenstein, Philosophical Investigations (New York: Macmillan Publishing CO., Inc. 1958), sec. 23.

${ }^{20}$ Wittgenstein, Investigations, p. 181.

${ }^{21}$ Merleau-Ponty, pp. 235-6. 
And compare the following from Merleau-Ponty and Wittgenstein, respectively:

The word is . . the presentation of a form of behavior of a linguistic act in its dynamic fullness. ${ }^{22}$

Words are deeds. ${ }^{23}$

Though they are speaking from - can I say - 'different worlds', the similarity and compatibility of the two methods is 'phenomenal'. The way words, sentences, are the phenomena of the linguistic world and are therefore the deeds of humans that make up such a social world, by the agreement of both philosophers, will later prove an important characteristic of the liaison between the phenomenal world of Merleau-Ponty and the social-linguistic world of Wittgenstein.

Wittgenstein, in one of the above quotations, mentioned the term 'language-games', which is a fundamental notion of his linguistic philosophy; ". . in one sense Wittgenstein's analysis can be seen as a refinement of Merleau-Ponty's phenomenology, namely, in his notion of language-games, his view of language as a variety of interlocking parts." 24 The language-game for him is roughly equivalent to the 'here' of Merleau-Ponty. As the place of the body-subject makes up a non-geometrical, lived space, so the speaker/listener has a 'here'. It is the languagegame in which he lives, 'where' he is at 'now'. The 'here' of the body-subject is 'wherever' the body-subject occurs; so it is with the language-game. It is 'wherever' the speaker is 'playing'. It determines its place and does not invent itself into an already objectified schema.

As the body-subject is always in relation to the 'there, 'the speaker is always, from his 'here', in relation to a 'there' which is ultimately other language-games in which he is at the moment not participating. As the body-subject can take his 'here' to a 'there' and that 'there' becomes his 'here,' so the speaker can change games, and play another. He is not confined

22 Merleau-Ponty, pp. 236.

${ }^{23}$ Ludwig Wittgenstein, Culture and Value (Chicago: The University of Chicago Press, 1980), p. 46 e.

${ }^{24}$ Spurling, p. 64. 
to any given place in the linguistic field which he inhabits. Wittgenstein said, "You must bear in mind that the languagegame is so to say something unpredictable. I mean: it is not based on grounds. It is not reasonable (or unreasonable). It is there - like our life." 25

As the motility of the body-subject is non-rational and a 'way of life' or way of 'being-in-the-world', so the languagegame is a way of 'being-in-the-linguistic-world.' However, there is the distinction between 'that' (the fact that) there is 'being-in-the-world' and 'how' (the way) there is being-inthe-world.' Where the subject occurs in the linguistic and phenomenal worlds is 'here.' But the 'way' being-in-the-world (linguistic) is 'here' is a 'form of life.' The way we are in the social world is linguistically. For, "... to imagine a language means to imagine a form of life." 26 As Wittgenstein later says, "Here the term 'language-game' is meant to bring into prominence the fact that the speaking of language is part of an activity, or of a form of life."27

One further point of continuity and similarity between the two philosophers is Merleau-Ponty's notion of 'horizons of meaning,' and Wittgenstein's notion of 'rules,' as noted earlier above. Merleau-Ponty's notion of horizons of meaning whether as an 'inner' horizon or 'outer' horizon is comparable to Wittgenstein's 'rules' because both concepts are boundaries that give the structure, outline and therefore the context of meaning to the basic components of the world of each: 'phenomena' and 'phenomenal field' in the former, 'words,' 'sentences' and 'games' in the latter. For Merleau-Ponty the inner horizon is that which separates the object of perception from the background and ultimately the phenomenal field. The outer horizon is that which bounds the phenomenal field itself. Likewise, for Wittgenstein 'rules' or the grammar' of languagegames is what separates and distinguishes words and sentence and context in 'this' game from other games, or what gives it the characteristic of being like or similar to another game with which it has a 'family resemblance.' Obviously, the 'grammar' of language as such is the perimeter of language or the

${ }^{25}$ Ludwig Wittgenstein, On Certainty (New York: Harper \& Row, Publishers, 1969), sec. 559.

${ }^{26}$ Wittgenstein, Investigations, sec. 19.

27Wittgenstein, Investigations, sec. 23. 
linguistic field. One cannot 'see' a horizon or beyond it, literally or existentially. Therefore, one 'blindly' - so to say stays within the boundaries that are 'there.' The rules that make up those horizons are not written down, but are blurred concepts that one operates without thinking. ${ }^{28}$ The above similarities between these two worlds reveal the existential compatibility and parallel of the two philosophies and worlds which they inhabit.

Perhaps the further question can be raised, and essentially so, concerning the junction of the social (linguistic) and phenomenal (pre-personal) worlds. It has already been stated that the phenomenal world is prior to the social world which is prior to the objective. Both philosophers see the latter as the ontologically least important and epistemologically most dependent world. The objective rests on the social and the phenomenal. So we should ask, 'where' is it that a junction of the first two worlds occurs? Perhaps the clearest way to approach such a question is to ask how far does Wittgenstein regress to his most fundamental point or foundation? Wittgenstein blatantly states the most primitive retreat available to him in the 'social/linguistic' world: "If I have exhausted the justification I have reached bedrock and my spade is turned. Then I am inclined to say: "This is simply what I do'."29 Prior to that point Wittgenstein cannot go with the criteria he has laid down. Obviously, he seems to 'jump in' at the center of the worlds, and perhaps he could be criticized for so limited a description of his foundation. However, it should be remembered that, working within a linguistic context, that is all he 'needs' to do. For he has assumed that human convention is as far as one can go in justifying human behavior of which language is an intricate part. Wittgenstein is not, clearly, denying any antecedent event or faculty to human convention, only saying that he does not know what it would be, and frankly, for his purposes it is irrelevant. How we perceive at the pre-personal level or even if we do is of no consequence to his position. How, for example, we obtained, created, etc., the capacity for language and language itself is of complete indifference. Wittgenstein needs no prior explanation

${ }^{28}$ Wittgenstein, Investigations. sec. 219.

${ }^{29}$ Wittgenstein, Investigations, sec. 217. 
or justification to accomplish what he does. A further explanation, as given by Merleau-Ponty, is indeed interesting and informative, but still entirely compatible with Wittgenstein's version of the social world. So, Wittgenstein is comfortable with the human deed as his foundation. However, at times he does seem to hint at something prior: "The origin and the primitive form of the language-game is a creation. Only from this can more complicated forms develop. Language I want to say - is a refinement, 'in the beginning was the deed'. "30

Wittgenstein sometimes encourages the reader to stop 'thinking' (i.e. intellectualizing) and look at the situation, or work, or game, etc. At these times he sounds very close to a Merleau-Pontian phenomenology in that he is surpassing an intellectual analysis in behalf of a perceptual or at least a prior 'something.' In two different works, for example, he says: "- but look and see ... To repeat: don't think, but look!"31 And again: "God grant the philosopher insight to what lies in front of everyone's eyes. ${ }^{\text {"32 }}$ So, though Wittgenstein maintains 'that is what I $d o^{\circ}$ as his foundation, certainly he leaves the door open for others to continue. Through that door Merleau-Ponty 'intentionally' strides toward what lies beyond it, namely the phenomenal world.

That is not to say that Merleau-Ponty does not place a great deal of importance on the social world, for the converse is true. In fact, without the social world, we could not even 'talk' about the phenomenal one. It would be banished from us, and it is impossible to see how any person could conceive of the prepersonal without the social institution of language. How could one conceive of that which is prior to that which one never knew or perceived? In that sense, then, the social world is before us and necessary for 'us.' Merleau-Ponty beautifully explains:

We must therefore rediscover ... the social world, not as an object or sum of objects, but as a permanent field or dimension of existence: I may well turn away from it, but not cease to be situated relatively to it. Our relationship to the social is, like our

${ }^{30}$ Wittgenstein, Culture and Value, p. 31e.

${ }^{31}$ Wittgenstein, Investigations, sec. 66.

${ }^{32}$ Wittgenstcin, Culture and Value, p. $63 \mathrm{e}$. 
relationship to the world, deeper than any express perception of any judgment ... . We must return to the social with which we carry about inseparably with us before any objectification ... The social is alrcady there when we come to know or judge it. ${ }^{33}$

Merleau-Ponty in the above quotation is certainly saying the same as Wittgenstein, and more. Both men undeniably see the social world as one of great existential importance. Merleau-Ponty has stated that we cannot get completely away from it, for it is deeper than any single perception alone. On the basis of the phenomenal world the social must rest, for Merleau-Ponty. However, both are intimately tied together. As shown in the above discussion of the phenomenal world, it is prior to the possibility for social experience. If one never has a perception, then one could never have a social world at all. Only from perception does it follow that there is a world, natural, social or otherwise. Only because there is perception can one know of the existence of other selves, language, etc. So perception and therefore the phenomenal world is of primary importance to ground any world.

Another truly interesting thing that both philosophers agree upon is that for their respective foundations to be foundations at all, each must admit that one can only acknowledge, believe, or have faith in it as the foundation on which to build. True, there may be good rational, phenomenal, or existential reasons to build upon 'that' one, but ultimately one has to admit to the 'faithing' or mere 'acknowledging' of such a point of origin. Although Merleau-Ponty is much clearer and more straightforward in his 'confession of faith,' Wittgenstein is equally in agreement, using only different words and phrases. Merleau-Ponty writes:

In experiencing a perceived truth, I assume that the concordance so far experienced would hold for a more detailed observation, I place my confidence in the world. Perceiving is pinning one's faith, at a stroke, in a whole future of experiences, and doing so in a present which never strictly guarantees the future; it is placing one's belief in a world. ${ }^{34}$

${ }^{33}$ Merleau-Ponty, p. 362.

${ }^{34}$ Merleau-Ponty, p. 297. 
Such a 'faith' is 'automatic' for without this confidence in the world and the experiences it makes possible, humankind would be hopelessly lost in a kaleidoscopic chaos of so-called 'perception' of a so-called 'world' by a so-called 'consciousness.' Taken a step further one could not use such words meaningfully for 'where' are the 'rules'? - or perhaps one could not even have those words or the concepts associated with them.

Wittgenstein would certainly agree here. Although his admission is a bit more vague than Merleau-Ponty's, if he truly believes that justification must end with 'that is what I do,' then he must believe in it and in what, if anything, lies prior to it. He already admitted that rational explanation and conceptual analysis could take him no further. Therefore, it is quite easy to see why Wittgenstein harbors a fierce belief in the 'agreement' by humans. In Remarks on the Foundations of Mathematics ${ }^{35}$ he speaks of the agreement of humans in what they 'do'; one of these things being language. Without faith or belief in the regularity and consistency of human conventions, Wittgenstein's concepts of 'language-games' and 'forms of life' would be undermined. However, those statements that do imply his confession still remain vague and sparse: "My life consists in my being content to accept many things."36 Wittgenstein discloses his belief in human 'deeds' by words like: 'accept,' 'agreement,' 'acknowledgement' (i.e. acceptance of - not admitting knowledge). Wittgenstein, like MerleauPonty, then, goes to his foundation only to believe in and beyond it. 'Believing' is just what they must 'do.'

The above paragraphs show the incredible similarities between Merleau-Ponty and Wittgenstein. From their point of junction, i.e. of the phenomenal and social worlds, through the parallels of their philosophies in those worlds, they share many of the same concepts, though each man says them differently. However, if Merleau-Ponty precedes Wittgenstein and the social world with his notion of perception and the phenomenal world, can he go beyond Wittgenstein, i.e. after the social world - not linearly, for that is the objective world, but rather, existentially? The phenomenal world is 'descriptively' prior to the social and the social to the

${ }^{35}$ Ludwig Wittgenstein, Remarks on the Foundations of Mathematics (Cambridge: The MIT Press, 1978) pp. 343-4, sec. 39.

${ }^{36}$ Wittgenstein, On Certainty, sec. 344. 
objective. Merleau-Ponty, however, could take the final 'truths' of Wittgenstein's linguistic philosophy and expand or broaden them. If we assume, as I shall for the sake of this essay, that absolute truth is the final at least existential, end or greatest end of life, then Merleau-Ponty indeed can transcend Wittgenstein's 'contexts' of language-games and forms of life to the 'context of contexts'. Unfortunately, Wittgenstein does not in the end offer a means of, or even grant the possibility of, uniting all of the truths of language-games into the 'truth of (particular) truths'. Many language-games may have 'family resemblance' as games of sports have similarities (e.g. soccer, football, baseball, tennis, and golf are all games that use some kind of a ball), but Wittgenstein intentionally chose the term 'game' for his notions because there is no one characteristic that is common to all games. We still know what a game is and how to use the word, but we cannot find a single characteristic that every game possesses: "I am saying that phenomena have no one thing in common which makes us use the same word for all, but that they are related to one another in many different ways. ${ }^{37}$ Indeed, they are related, but they cannot be united in a single context.

Merleau-Ponty, on the contrary, speaks of a notion that is like a 'context of contexts'. This, however, could not be the object of consciousness, because to be such would require the body-subject to 'be' outside the world to perceive it. If, then, this unity of truth, the 'context of contexts,' is absolute truth in some sense, it can never be known. Indeed, this meshing of the truths of particular language-games or of forms of life is interesting and perhaps even desirable. I am not, however, convinced that it can be more than hopeful speculation on the part of Merleau-Ponty. If it cannot be perceived, because that would violate the basis of perception in requiring the bodysubject to be being-outside-the-world, then there is no rational, linguistic or phenomenal basis on which to assume such. If Merleau-Ponty can provide a way to support this transcendental context, so be it. This, however, would be in Wittgensteinian terms a 'game of games' and therefore would be the characteristic that unites all of the games into this new game. That would undermine the very notion of 'game' that

37Wittgenstein, Investigations, sec. 65 . 
Wittgenstein is working with in the concept of 'languagegames', which is foundational for the social world as he interprets it. For any particular game is grounded in 'rules' that one follows - as it were - 'blindly' (comparable to MerleauPonty's 'inner horizon'). The 'rules' or 'grammar' of the 'game' of all language-games would force them to share that grammar in common. Therefore, the entire parallelism drawn in this essay between the phenomenological Merleau-Ponty and the linguistic Wittgenstein is irreparably shattered into infinity, and their compatibility is a gross illusion.

However, such is not the case. Merleau-Ponty cannot prove the existence of a 'context of contexts', but may only speculatively posit that possibility to lend existential benefits to the world and the subjects that greet it. In fact, MerleauPonty's position seems to be far closer to Wittgenstein's than one might at first imagine. Merleau-Ponty's notion of 'context of contexts' perhaps could more accurately be interpreted as an elaborate system of 'family resemblances'. There may be many resemblances, similarities, or relations, but the absolute will never be reached. In that sense there 'is' no 'context of contexts.' Spurling explains:

Self-understanding can never be total. This is what MerleauPonty means when he [says] . . . 'truth is always to come'. Truth never completely arrives because it can never be absolute and eternal. And so, for phenomenology ... there can only be a truth within a situation: 'And since we have an idea of truth, since we are in truth and cannot escape it, the only thing left for me to do is to define a truth in the situation. ${ }^{38}$

As Wittgenstein will say that what counts as the truth in any given situation depends on the language-game one is playing, so Merleau-Ponty has situational-relative truths. Phenomenally as well as linguistically one can only speak of truths in relation to the background, field, horizon or language-game, respectively. To posit more is to step beyond what the world presents us in perception or human convention reveals to us in what we 'do'. As long as the 'context of contexts' is never reached, this absolute truth - if you will - remains antipodal to the horizon of meaning, and the above synthesis of Merleau-

${ }^{38}$ Spurling, p. 105. 
Ponty and Wittgenstein can survive. The realization of such a context would not only obliterate the above synthesis, but perhaps their respective philosophical positions as well, if it were 'true'.

Wittgenstein and Merleau-Ponty both are doing a descriptive philosophy as opposed to an explicatory one. Spurling claims that, "It is this opposition to any form of explanation, .... which makes Wittgenstein's later philosophy in many ways comparable to phenomenology. "39 Yet it would be a mistake and an oversimplification of Wittgensteinian philosophy to read him as merely or exclusively descriptive. This is a claim that may be true of his followers and those who are influenced by his philosophy, but to read Wittgenstein himself so would distort his existential 'depth'. For "Wittgenstein can be read from a transcendental or a descriptive perspective ..."40 Some will go on to declare as Spurling, in the above quote, that one must interpret Wittgenstein as one or the other, transcendental or descriptive. This is simply to construct a false dichotomy. One theme of this essay has been an attempt to read Wittgenstein as both descriptive (as most radical Wittgensteinians agree) and transcendental (as synthetic with phenomenology, especially Merleau-Ponty). Wittgenstein has been criticized by phenomenologists for striving for complete clarity. ${ }^{41}$ That does not mean that he believes it is any more reachable than Merleau-Ponty's absolute truth - 'context of contexts'. If one can see Wittgenstein's ideas from perhaps a 'non-Anglo' perspective, and 'return to the Continent', then it will be clear that he is speaking descriptively and transcendentally. One will then see the existential and even phenomenological aspects of Wittgensteinian philosophy.

The synthesis above shows quite clearly that MerleauPonty precedes Wittgenstein descriptively and logically and that only on the basis of a transcendental assumption can he succeed Wittgenstein, go beyond. Existentially, this succession is important for it points being-in-the-world toward a goal, toward that ultimate 'context'. Wittgenstein, however, has no

${ }^{39}$ Spurling, p. 176.

${ }^{40}$ Spurling, p. 177.

${ }^{41}$ Spurling, pp. 177-8. 
place to point toward or goal to point at - existentially. Life is what we 'do', which is based on the phenomenal world, but it strives to no ultimate goals and it is difficult to see how any such goal could be useful, save existentially. Merleau-Ponty agrees with this grounding in deeds or action for he says: "My life', my 'total being' are not dubious constructs, ... . but phenomena which are indubitably revealed to reflection. It is simply a question of what we are doing. ${ }^{\text {"42 }}$ This clearly shows the existential dependence of the two worlds as represented by Merleau-Ponty and Wittgenstein. The social world could not 'exist' without the phenomenal in which it is grounded, and the phenomenal, if never known by 'us' and never 'spoken' of would be secluded and segregated in an existential isolation that is caged in the perception of single consciousness - however many there may be. Depending on whether one stands on 'this' side or 'that', on the one hand the transcendentally parallel worlds are given with the phenomenal world as the 'background' for the social, and on the other the social world is the 'background' for the phenomenal. The latter may indeed be logically prior, but both forever remain - existentially mutually dependent. Therefore, the first world of MerleauPonty is prior and parallel to the social world of Wittgenstein, and these are not existing as either/or, but rather as both/and. They together remain forever 'condemned to meaning'.

${ }^{42}$ Merleau-Ponty, p. 380. 